\title{
Impact of a teaching attending physician on medical student, resident, and faculty perceptions and satisfaction
}

\author{
Tara N. Cassidy-Smith, MD*; J. Hope Kilgannon, MD*; Andrew L. Nyce, MD*; \\ Michael E. Chansky, MD*; Brigitte M. Baumann, MD, MSCE*
}

\section{ABSTRACT}

Objectives: To determine if a dedicated teaching attending for medical student education improves medical student, attending physician, and resident perceptions and satisfaction.

Methods: Two dedicated teaching attending physician shifts were added to the clinical schedule each week. A before-after trial compared medical student evaluations from 2000 to 2004 (preteaching attending physician) to medical student evaluations from 2005 to 2006 (teaching attending physician). Attending physician and resident perceptions and satisfaction with the teaching attending physician shifts using a 5 -point Likert-type scale ( $1=$ poor to $5=$ excellent) were also assessed.

Results: Eighty-nine (100\%) medical students participated, with 63 preteaching attending physician and 26 teaching attending physician rotation evaluations. The addition of teaching attending physician shifts improved mean medical student satisfaction with bedside teaching (4.1 to 4.5$)$, lecture satisfaction (4.2 to 4.8 ), preceptor scores (4.3 to 4.8 ), and perceived usefulness of the rotation (4.5 to 5.0) (all $p<0.05$ ). Thirteen attending physicians (93\%) participated in the crosssectional questionnaire. The addition of teaching attending physician shifts improved faculty ratings of their medical student interactions by $\geq 1.5$ points for all items ( $p \leq 0.001$ ). Faculty perceptions of their resident interactions improved for quality of bedside teaching (3.1 to 4.0), their availability to hear resident presentations ( 3.4 to 4.2 ), and their supervision of residents (3.4 to 4.1$)(p \leq 0.01)$. Residents $(n=35)$ noted minor improvements with the timeliness of patient dispositions, faculty bedside teaching, and attending physician availability. Conclusions: The addition of select teaching attending physician shifts had the greatest effect on medical student and faculty perceptions and satisfaction, with some improvements for residents.

\section{RÉSUMÉ}

Objectifs : Déterminer si un enseignement spécialisé destiné aux étudiants en médecine améliore les perceptions et la satisfaction des étudiants en médecine, des médecins traitants et des résidents en médecine.

Méthodes : Deux quarts de médecins traitants enseignants spécialisés ont été ajoutés à l'horaire de travail clinique chaque semaine. Un essai de type " avant et après " a permis de comparer les évaluations des étudiants en médecine entre 2000 et 2004 (médecin traitant avant sa certification) aux évaluations des étudiants en médecine entre 2005 et 2006 (médecin traitant enseignant). On a également comparé les perceptions et la satisfaction des médecins traitants et des résidents en médecine aux quarts de médecins traitants enseignants à l'aide d'une échelle de type Likert en 5 points ( 1 = médiocre à $5=$ excellent).

Résultats : Quatre vingt-neuf (100\%) étudiants en médecine ont participé à l'étude, et les évaluations des rotations ont porté sur 63 médecins traitants avant leur certification et 26 médecins traitants enseignants. L'addition des quarts de médecins traitants enseignants a amélioré la satisfaction

Department of Emergency Medicine, Cooper University Hospital and University of Medicine and Dentistry of New Jersey-Robert Wood Johnson Medical School at Camden, Camden, NJ.

Correspondence to: Dr. Brigitte M. Baumann, Department of Emergency Medicine, Cooper University Hospital, One Cooper Plaza, Camden, NJ 08103; baumann-b@cooperhealth.edu.

Submitted May 8, 2010; Revised NA; Accepted June 23, 2010.

Preliminary findings of a subset of this data were presented in two parts: as a poster presentation at the Society for Academic Emergency Medicine annual meeting, San Francisco, CA, May 2006, and as a poster presentation at the American College of Emergency Physicians annual meeting, New Orleans, LA, October 2006.

This article has been peer reviewed. 
moyenne des étudiants en médecine quant à l'enseignement au chevet des malades $(4,1$ à 4,5$)$, à la satisfaction des cours $(4,2$ à 4,8 , aux scores des précepteurs ( 4,3 à 4,8$)$, et à I'utilité perçue de la rotation $(4,5$ à 5,0$)$ (toutes les valeurs $p<0,05)$. Treize médecins traitants $(93 \%)$ ont participé au questionnaire transversal. L'addition des quarts de médecins traitants enseignants a amélioré le classement par la faculté de ses interactions avec les étudiants en médecine de $\geq 1,5$ point pour tous les items $(p \leq 0,001)$. Les perceptions par la faculté de ses interactions avec les résidents se sont améliorées quant à la qualité de l'enseignement au chevet des malades $(3,1$ à 4,0$)$, à leur disponibilité à entendre les présentations des résidents en médecine $(3,4$ à 4,2$)$, et à leur supervision des résidents $(3,4$ à $4,1)(p \leq 0,01)$. Les résidents en médecine $(n=35)$ ont observé des améliorations mineures quant à la ponctualité des dispositions des patients, à l'enseignement au chevet des malades par la faculté et à la disponibilité des médecins traitants.

Conclusions : L'addition de certains quarts de médecins traitants enseignants a eu un effet maximal sur les perceptions et la satisfaction des étudiants en médecine et de la faculté, et apporté certaines améliorations pour les résidents en médecine.

Keywords: clinical clerkship, education, emergency medicine, internship and residency, teaching methods
Bedside teaching has been an integral part of medical education, yet over the past century, the classic bedside model refined by Sir William Osler has suffered. Increasing medical school class sizes and educators' needs to impart vast quantities of information within a limited time period have led educational efforts away from the bedside and into the lecture hall. This trend has reversed somewhat over the past 20 years owing to concerns about the increasing depersonalization of medicine. ${ }^{1,2}$ With a renewed emphasis on small-group clinical interactions, a core element in current education of aspiring physicians includes real-time feedback on their history and physical examination skills at the bedside from seasoned clinicians. ${ }^{3-5}$

Emergency departments (EDs) offer many opportunities for bedside teaching owing to high volumes of acutely ill patients and the need for procedural interventions. In spite of these opportunities, bedside teaching in the ED has become increasingly challenging. Patient encounters must be brief, patient acuity may interfere with teaching moments, and, most recently, ED crowding may limit the number of educational opportunities owing to privacy and space issues as well as limited faculty availability for dedicated medical student instruction. ${ }^{3,6-10}$ These challenges have led to increasing undergraduate and graduate trainee dissatisfaction with their clinical emergency medicine didactic experiences., ${ }^{3,11,12}$

As with other institutions, our ED has experienced a dramatic increase in annual patient volume and acuity over the past decade. Accompanying these increases, there was a steep decline in fourth-year medical student rotation satisfaction, particularly regarding the paucity of attending physician-initiated bedside teaching. Accompanying the poor clerkship reviews, there was also a decline in applications to emergency medicine residency programs from medical students at our institution, which adversely affected our residency program. Attending physicians expressed frustration with balancing patient care and maintaining student satisfaction. Students' cases required additional faculty time, documentation, and supervision, and these responsibilities were interfering with patient care and throughput efforts. ${ }^{13}$ After careful deliberation, faculty members agreed to increase their teaching efforts and pilot a potential solution. Thus, a limited number of dedicated "medical student teaching attending physician shifts" were added to our ED's clinical faculty schedule, and this study hypothesized that the addition of teaching attending physician shifts would improve medical student satisfaction with the rotation as well as faculty and resident perceptions of their clinical experiences.

\section{METHODS}

\section{Design and objectives}

This study followed a cross-sectional before-after survey design. The primary objective was to determine if teaching attending physician shifts would improve medical students' satisfaction with their ED elective. The secondary objectives were to determine if there was any improvement in emergency medicine resident and attending physician perception and satisfaction scores with the initiation of teaching attending physician shifts.

\section{Participants and setting}

Responses from a standardized anonymous questionnaire that had been collected from all fourth-year medical students prior to the initiation of teaching attending physician shifts served as baseline data 
(July-September 2000-2004). Completion of these questionnaires was mandatory for all students who completed the emergency medicine elective. The emergency medicine rotation was an elective offered July to September, not a required component of the medical student curriculum. The identical, anonymous questionnaire was distributed to students after the addition of dedicated teaching attending physician shifts (July-September 2005-2006). Students who rotated through the ED in 2005 and 2006 all experienced teaching attending physician shifts. For these students, completion of the rotation evaluation was no longer mandatory. Instead, students were asked to voluntarily complete these evaluations as part of this investigation. All medical students were blinded to the objectives of this investigation.

Emergency medicine residents and faculty were also asked to complete standardized questionnaires that included items from the student survey. To be eligible to participate, residents and attending physicians had to work at least one clinical shift during the teaching attending physician periods. Items specifically pertaining to the experiences of the teaching attending physician were answered only by faculty who completed at least one teaching attending physician shift during the course of this investigation. Owing to the nature of the survey items, blinding was not possible for these two groups.

The investigation was conducted at an inner-city academic ED with an initial annual census of 43,000 in 2000, which increased to 49,000 (14\% increase) by 2006 . The ED has an accredited 3-year categorical emergency medicine residency program and is the major clinical training site for the medical school. All attendings are board certified or board eligible in emergency medicine, with academic appointments at the medical school. The retrospective portion of the study (2000-2004) was deemed exempt and the prospective portion was approved by our Institutional Review Board. For prospective enrolment, potential participants (medical students, residents, and attending physicians) were informed that participation in this satisfaction study was completely voluntary. Completion of the questionnaire demonstrated implied consent.

\section{Intervention}

During July to September 2005 and 2006, two additional medical student teaching shifts per week were added to the attending physician clinical schedule.
The teaching attending physician program was limited to July to September because the majority of subinterns rotated in the ED during these months. Teaching attending physician shifts were 8 hours in duration. During the first 6 hours, medical students and the teaching attending physician focused on the clinical care of ED patients. The remaining 2 hours were allotted for an informal didactic session, which was in addition to the core medical student lecture series. Although teaching attending physician shifts were initially somewhat fluid in structure, the shifts evolved in such a manner that fourth-year students were encouraged to pick up new patients and present them to the teaching attending physician, similar to a conventional shift. At times, to prevent a backlog of cases and to allow for bedside teaching, students were occasionally paired up to see their next new patient together. This typically occurred when the next patient case required a procedure (i.e., a complicated laceration repair). Typically, procedures were observed by all students, with the teaching attending physician providing instruction and procedural guidance at the bedside.

Of 14 faculty members, 6 served as teaching attending physicians during the study period and participated in conventional shifts. Faculty members volunteered to serve as teaching attending physicians, and all were core faculty with a strong interest in medical education. During the teaching shifts, the designated teaching attending physician was solely responsible for the care of all patients seen by medical students. A teaching group was composed of one dedicated teaching attending and two to three medical students. This group worked in parallel with the conventional care team(s), which consisted of residents and one or two clinical attending physicians. Teaching attending physicians did not precept any other ED cases during their shifts. Likewise, the regularly scheduled attending physicians supervised only resident cases. During teaching attending physician shifts, the residents no longer competed with medical students to present cases or for attending physician supervision. Medical students were assigned to 14-15 ED shifts during their rotation and approximately $25 \%$ of these were teaching attending shifts.

\section{Survey content and administration}

Using a 5 -point Likert-type scale $(1=$ poor to $5=$ excellent), medical students were asked to rate the 
following: faculty bedside teaching, lecture quality, quality of patient care, adequacy of supervision, usefulness of the rotation, preceptor experience, case logbook usefulness, and formal oral case presentation, which was part of each student's final examination. Additional space was provided to allow students to write in anonymous comments.

For the physician portion of our study, we conducted a standardized, cross-sectional survey of attending and resident physicians. Attending physicians rated the impact of the teaching attending physician on the following medical student factors: attending physician availability to precept, timeliness of patient workup and disposition, ability to supervise medical student, ability to provide bedside teaching, student autonomy, and overall quality of medical student patient care during both teaching and nonteaching attending physician shifts. All attending physicians rated the following: availability to listen to resident presentations, availability to supervise residents, ability to provide resident bedside teaching, overall resident autonomy, and quality of resident-provided patient care during teaching and conventional attending physician shifts.

The resident questionnaire asked participants to rate the availability of an attending physician to precept their case presentations, timeliness of initiating patient care (e.g., laboratory testing, radiographs), timeliness of patient disposition, amount of attending physician supervision they received, quality of bedside teaching they received, level of autonomy they were given for overall management and treatment plan of patients, and their overall self-perceived quality of patient care.

Questionnaires were distributed during faculty and resident meetings to increase the response rate.
Nonresponders were provided with a second copy of the survey 2 weeks later as a reminder. No further prompts were given. For all questionnaires, responses were scaled on a 5-point Likert-type scale, with $1=$ poor, $2=$ fair, $3=$ adequate, $4=\operatorname{good}, 5=$ excellent.

\section{Data analysis}

Medical student survey responses from 2000 to 2004 (preteaching attending physician) were compared to those from 2005 to 2006 (postintervention phase). Satisfaction scores are presented as means with standard deviations. Student $t$-tests were used for medical student data comparisons, and paired $t$-tests were used for resident data. Nonparametric testing was used for attending physician satisfaction scores, which were not normally distributed. To maintain consistency in satisfaction ratings, however, means with standard deviations are provided for all data, irrespective of normality. A $p$ value $<0.05$ was the cutoff for statistical significance. Data analysis was conducted with SPSS 15 (SPSS Inc., Chicago, IL).

\section{RESULTS}

Of 89 medical students who completed the emergency medicine rotation, 63 (preteaching attending physician) and 26 (teaching attending physician) medical student evaluations were returned from 2000 to 2006 (response rate $=100 \%$ ). Mean satisfaction with bedside teaching, lectures, preceptors, logbooks, and impression of overall usefulness of the rotation were all significantly improved (Table 1). Table 2 provides qualitative data obtained from student evaluations, both pre- and postintervention.

\begin{tabular}{llcc|}
\hline Table 1. Medical student satisfaction & \\
\hline & $\begin{array}{c}\text { Without TA, mean } \\
\text { (SD) } \\
\text { Medical student satisfaction ratings }\end{array}$ & $\begin{array}{c}\text { With TA, mean } \\
\text { (SD) }\end{array}$ & \\
\hline Quality of bedside teaching & $4.1(0.9)$ & $4.5(0.6)$ & 0.02 \\
Lecture quality & $4.2(0.7)$ & $4.8(0.4)$ & $<0.001$ \\
Quality of patient care & $4.3(0.7)$ & $4.5(0.6)$ & 0.16 \\
Adequacy of supervision & $4.2(1.0)$ & $4.4(0.7)$ & 0.32 \\
Usefulness of the rotation & $4.5(0.8)$ & $5.0(0.2)$ & $<0.001$ \\
Preceptor experience & $4.3(0.9)$ & $4.8(0.6)$ & 0.01 \\
Formal case presentation experience & $4.1(0.8)$ & $4.2(0.7)$ & 0.66 \\
Logbook usefulness & $3.2(1.2)$ & $3.8(0.8)$ & 0.01 \\
\hline SD = standard deviation; TA = teaching attending physician. & & &
\end{tabular}


Table 2. Selected comments from anonymous medical student ED rotation evaluation

Comments from students who only experienced conventional shifts

"(Quality of bedside teaching) varied greatly depending on situation of ER."

"I would have liked to have gotten feedback earlier."

"Learning experience was good, but often had to spend too much time waiting around to present."

"I didn't feel like I knew what was expected of me. Everyone was very nice, but I was never given any constructive criticism."

"In general, I like when attendings say 'So what do you want to do,' and I hate when [they] just tell me what we're going to do.'

"I know [it's] busy at time[s] and students/residents/attendings can get deeply involved in 1 or 2 patients, but would appreciate if residents or attendings can give students a heads-up on interesting patients or findings."

"Enjoyed [the community site]. Saw more patients here than at (the academic ED) because less residents and students (and) more time with patients rather than waiting for attending to present."
Comments from students who experienced both conventional and teaching attending physician shifts

"I liked having mandatory scheduled time to discuss cases and get some teaching because it is sometimes too busy in the ED during a shift to get all of that."

"A great rotation with plenty of teaching at lecture and at the bedside."

"Attendings were some of the best teachers I've had all year."

"I felt like they made us (medical students) a priority."

"Great teaching shift(s)!"

"The teaching shifts are a great addition to the rotation."

"The teaching shifts were very helpful... Overall, best experience in med school."

"The teaching staff were superb and clearly dedicated to [the] rigors of academia and excellent patient care. I leave here with an excellent impression of the program and the people in it."

"Excellent rotation. It is evident that a lot of thought goes into teaching, especially with younger faculty who spend time teaching on teaching shifts."
Thirteen attending physicians (93\%) participated in the prospective, cross-sectional survey. Faculty noted improvements in all medical student items, with the greatest improvements in availability to listen to medical student presentations, timeliness to initiation of laboratory testing, timeliness of patient disposition, and ability to adequately supervise medical students (Table 3). Likewise, faculty perceptions of their availability to hear resident presentations and provide resident supervision and resident bedside teaching were higher for teaching attending physician shifts compared to nonteaching attending physician shifts (Table 4).

Thirty-nine (90\%) emergency medicine residents completed the survey. Residents noted improved attending physician availability, timeliness of patient discharge, and attending physician bedside teaching for residents (Table 5).

\section{DISCUSSION}

The ED is an ideal setting for bedside teaching. Despite the broad range of acuity, presenting complaints, and opportunities for procedures, limited staffing, space, and time represent barriers to bedside teaching. ${ }^{3,5,7}$ The recent crowding epidemic has further burdened the efforts of emergency clinicians, requiring academic faculty to spend more time and effort on clinical, administrative, and systems needs and, subsequently, less time on learner education. ${ }^{12}$ These escalating demands have resulted in the erosion of bedside teaching and dissatisfaction among trainees.

Table 3. Attending physician perceptions of their interactions with medical students

\begin{tabular}{|c|c|c|c|}
\hline Attending physician perceptions & $\begin{array}{l}\text { Nonteaching attending } \\
\text { physician shifts, mean (SD) } \\
(n=13)\end{array}$ & $\begin{array}{l}\text { Teaching attending } \\
\text { physician shifts, }{ }^{\dagger} \text { mean (SD) } \\
\qquad(n=6)\end{array}$ & $p$ value* \\
\hline Availability for MS presentations & $2.2(0.7)$ & $4.8(0.4)$ & $<0.001$ \\
\hline Timeliness to initiation of workup & $1.8(0.6)$ & $4.5(0.8)$ & $<0.001$ \\
\hline Timeliness to patient disposition & $2.1(0.7)$ & $4.3(0.5)$ & $<0.001$ \\
\hline Ability to adequately supervise MS & $2.1(0.9)$ & $4.3(0.5)$ & $<0.001$ \\
\hline Ability to provide bedside teaching to MS & $3.1(0.8)$ & $4.8(0.4)$ & 0.001 \\
\hline Level of student autonomy & $2.7(0.6)$ & $3.8(0.8)$ & $<0.01$ \\
\hline Overall quality of MS patient care & $3.0(0.8)$ & $4.5(0.5)$ & 0.001 \\
\hline
\end{tabular}


Table 4. Attending physician perceptions of their interactions with residents

\begin{tabular}{|c|c|c|c|}
\hline Attending physician perceptions & $\begin{array}{c}\text { Nonteaching attending } \\
\text { physician shifts, mean } \\
\text { (SD) } \\
(n=13)\end{array}$ & $\begin{array}{c}\text { Teaching attending } \\
\text { physician shifts, mean } \\
\text { (SD) } \\
(n=13)\end{array}$ & $p$ value* \\
\hline Availability for resident presentations & $3.4(0.5)$ & $4.2(0.6)$ & 0.003 \\
\hline Ability to adequately supervise residents & $3.4(0.7)$ & $4.1(0.5)$ & 0.01 \\
\hline Ability to provide bedside teaching to residents & $3.1(0.7)$ & $4.0(0.4)$ & 0.002 \\
\hline Level of resident autonomy & $3.7(0.6)$ & $4.0(0.5)$ & 0.1 \\
\hline Overall quality of resident patient care & $3.8(0.6)$ & $4.1(0.6)$ & 0.1 \\
\hline
\end{tabular}

Undergraduate medical education, in particular, brings a unique set of challenges to the ED. Medical student inexperience and limited medical knowledge are often at odds with the high acuity of ED patients and the chaotic ED environment. ${ }^{14}$ Preconceived notions of health care staff may further limit medical student educational experiences. For example, it is often thought that medical students increase patient throughput times in the ED despite evidence demonstrating otherwise. ${ }^{15}$ In an effort to address these concerns and improve the educational experience, our faculty acknowledged that additional interactions with the attending physicians were needed.

Unfortunately, the literature on medical student education in the ED setting is limited. Penciner outlined strategies to promote more effective and efficient teachers, which include having clinician educators, seizing teachable moments, providing early feedback, and exposing trainees to good "teaching cases." Although these recommendations are based on educational theory and inpatient experiences, they still have not been formatively tested in a crowded ED setting. Others have introduced ED-based computer tutorials as an adjunct to medical student bedside teaching. ${ }^{16}$ One concern with this innovation is that the traditional, experienced human bedside teacher is now simply replaced with an interactive computer module. A second concern is that computer modules may not address the complexities of medical expertise as defined by the Accreditation Council for Graduate Medical Education (ACGME) core competencies or the Canadian Medical Education Directives for Specialists. This, too, was not a satisfactory solution for our dilemma because the primary complaint of students was the dearth of bedside teaching from seasoned clinicians.

Our proposed solution was the institution of a dedicated teaching shift. To our knowledge, the only other ED that has documented its experiences with a dedicated teaching attending physician is at Emory University. ${ }^{17}$ The Emory program initiated an "academic attending physician" teaching shift, where faculty freed from clinical duties provided unstructured bedside teaching three times a week, combined with a limited lecture series. Over time, the program evolved to a once-weekly structured educational experience primarily based on prepared faculty lectures in lieu of bedside didactics. ${ }^{17}$

\begin{tabular}{|c|c|c|c|}
\hline Resident perceptions & $\begin{array}{c}\text { Nonteaching attending } \\
\text { physician shift, mean } \\
\text { (SD) } \\
(n=35)\end{array}$ & $\begin{array}{c}\text { Teaching attending } \\
\text { physician shift, mean } \\
\text { (SD) } \\
(n=35)\end{array}$ & $p$ value \\
\hline Attending physician availability to hear resident presentations & $3.9(0.7)$ & $4.3(0.6)$ & 0.001 \\
\hline Timeliness to initiation of workup & $3.7(0.7)$ & $3.9(0.6)$ & 0.16 \\
\hline Timeliness of patient disposition & $3.7(0.7)$ & $3.9(0.6)$ & 0.003 \\
\hline Attending physician supervision of residents & $4.0(0.6)$ & $4.3(0.6)$ & 0.18 \\
\hline Attending physician bedside teaching to residents & $3.5(1.0)$ & $3.9(0.9)$ & 0.001 \\
\hline Level of resident autonomy & $4.0(0.6)$ & $4.1(0.6)$ & 0.06 \\
\hline Overall quality of resident patient care & $3.9(0.6)$ & $4.2(0.5)$ & 0.06 \\
\hline
\end{tabular}


Unlike our study, the Emory intervention was primarily focused on resident education and none of the teaching attending physician programs have ever been formally evaluated. ${ }^{17}$

In this study, the results demonstrate that the intervention improved medical students' satisfaction with bedside teaching, their preceptor experience, and perceived overall usefulness of the rotation. Additionally, lecture quality ratings also improved. This was expected because 2 hours of each teaching attending physician shift were specifically dedicated to didactics in addition to the traditional emergency medicine medical student lecture series. The improvement in logbook usefulness may reflect increased exposure to "interesting" cases, which, qualitatively, did occur during teaching attending physician shifts.

There were no significant differences in student ratings of the quality of patient care and the adequacy of supervision. There was also no significant difference in the formal case presentation experience. This was expected because this oral presentation was part of each student's final examination, was not contingent on the availability of a supervisory attending physician, and essentially served as a control variable.

The implementation of teaching attending physician shifts also favourably influenced faculty satisfaction. The attending physician survey demonstrated improvement in all dimensions for attending physicianmedical student interactions, including the timeliness of initiation of the patient's workup (i.e., ordering laboratory tests or radiographs), as well as perceived timeliness to patient disposition. Although we did not record actual time intervals, these results suggest that implementation of a teaching attending physician program may lead to improved patient throughput times for medical student cases. Further study is needed to determine if these perceptions are accurate.

Compared to conventional shifts, teaching attending physician shift data also demonstrated significant improvements in availability to hear resident presentations, as well as increased ability to supervise residents and provide resident bedside teaching. The addition of the teaching attending physician uniformly improved satisfaction scores of all attending physicians. It is probable that the presence of a teaching attending physician enabled conventional clinical faculty to spend more time teaching and supervising residents because they were not responsible for medical student supervision. From a faculty standpoint, the teaching attending physician program improved overall medical student and resident teaching and preceptorship.

Our study demonstrated that timeliness to patient disposition and attending physician bedside teaching and availability to precept resident cases were improved. The meaning of the limited improvement in resident ratings is unclear. Perhaps more enthusiastic or experienced faculty self-selected to serve as medical student teaching attending physicians, limiting their number of regular clinical shifts with our residents. In addition, items that did not demonstrate improvement (i.e., level of resident autonomy) may be factors that residents perceive as independent from the availability of an attending physician. Alternatively, given that there were only about eight teaching attending physician shifts per month, residents may not have noticed as much of an improvement because they often worked at least twice as many shifts within the same time period. Furthermore, if a resident worked nights or evenings, he or she would not indirectly benefit from the addition of a third (teaching) attending physician because these shifts occurred only during daytime hours.

Given the improvements in both qualitative and quantitative satisfaction measures, we respectfully conclude that our intervention did achieve its objective.

\section{LIMITATIONS}

There are several limitations to this investigation that deserve mention. First, our study was conducted at only one academic centre, and our results may not be applicable to other settings. Second, because no formal definitions were provided for the survey items, individual interpretation of terms may have affected the results. The lack of formal definitions was intentional because we were limited by our preintervention medical student data set. To allow for comparisons, we used the same medical student clerkship evaluation and did not alter the questions, nor did we provide clarification of individual items, to maintain consistency between pre- and postintervention groups. Third, the postintervention data set was small. Unfortunately, by the fall of 2007, the clerkship became mandatory for all fourth-year medical students, and the evaluation form was substantially altered. Fourth, perceptions and satisfaction with teaching methods may or may not translate into actual educational value and improved learning. In addition, our increases in medical student satisfaction scores 
were relatively small (approximately 10-15\% improvement). Finally, we have not completed a formal analysis of our costs. For our department to institute this program, all attending physicians were required to work additional shift time, and this may represent a significant expense to an already financially stretched ED. Teaching attending physicians had regular clinical shifts replaced by teaching shifts, and the clinical faculty worked additional hours to cover the lost clinical shift time. These additional clinical and teaching hours were, to a large extent, supported by our ED and medical school. We are uncertain if this level of commitment to undergraduate emergency medicine education is present at other institutions.

\section{CONCLUSION}

We demonstrated that the addition of a dedicated medical student teaching attending physician significantly improved medical student and ED faculty satisfaction and had a positive effect on a select number of resident factors. There are several potential barriers to the implementation of the teaching attending physician, and we recommend future evaluations of the overall strategy in other settings and modifications to the strategy (e.g., employing senior residents, shortening or reducing the number of shifts).

Competing interests: None declared.

\section{REFERENCES}

1. Drees BM, Arnold L, Jonas HS. The University of MissouriKansas City School of Medicine: thirty-five years of experience with a nontraditional approach to medical education. Acad Med 2007;82:361-9.

2. Maheux B, Beaudoin C, Berkson L, et al. Medical faculty as humanistic physicians and teachers: the perceptions of students at innovative and traditional medical schools. Med Educ 2000;34:630-4.
3. Aldeen AZ, Gisondi MA. Bedside teaching in the emergency department. Acad Emerg Med 2006;13:860-6.

4. LaCombe MA. On bedside teaching. Ann Intern Med 1997; 126:217-20.

5. Ramani S, Orlander JD, Strunin L, et al. Whither bedside teaching? A focus-group study of clinical teachers. Acad Med 2003;78:384-90.

6. Kelly SP, Shapiro N, Woodruff M, et al. The effects of clinical workload on teaching in the emergency department. Acad Emerg Med 2007;14:526-31.

7. Penciner R. Clinical teaching in a busy emergency department: strategies for success. CFEM 2002;4:286-8.

8. Bandiera G, Lee S, Tiberius R. Creating effective learning in today's emergency departments: how accomplished teachers get it done. Ann Emerg Med 2005;45:253-61.

9. Heins A, Farley H, Maddow C, et al. A research agenda for studying the effect of emergency department crowding on clinical education. Acad Emerg Med 2005;12:529-32.

10. Shayne $\mathrm{P}$, Lin M, Ufberg JW, et al. The effect of emergency department crowding on education: blessing or curse? Acad Emerg Med 2009;16:76-82.

11. DeSantis M, Marco CA. Emergency medicine residency selection: factors influencing candidate decisions. Acad Emerg Med 2005;12:559-61.

12. Atzema C, Bandiera G, Schull MJ. Emergency department crowding: the effect on resident education. Ann Emerg Med 2005;45:276-81.

13. Documentation guidelines for evaluation and management (E/M) services. Available at: http://www.cms.hhs.gov/ MLNEdWebGuide/25_EMDOC.asp (accessed January 22, 2010).

14. Thurgur L, Bandiera G, Lee S, et al. What do emergency medicine learners want from their teachers? A multicenter focus group analysis. Acad Emerg Med 2005;12: 856-61.

15. Chan L, Kass LE. Impact of medical student preceptorship on ED patient throughput time. Am 7 Emerg Med 1999;17: 41-3.

16. Pusic MV, Pachev GS, MacDonald WA. Embedding medical student computer tutorials into a busy emergency department. Acad Emerg Med 2007;14:138-48.

17. Shayne P, Heilpern K, Ander D, et al. Protected clinical teaching time and a bedside clinical evaluation instrument in an emergency medicine training program. Acad Emerg Med 2002;9:1342-9. 